\title{
ABUNDANCE AND DISTRIBUTION OF VASCULAR PLANTS \\ IN THE BIGHORN CANYON NAITONAL RECREATION AREA
}

\author{
Dennis H. Knight \\ Department of Botany \\ University of Wyoming \\ Laramie \\ and \\ Robert Lichvar and Ellen Collins \\ Wyoming Natural Heritage Office \\ Cheyenne
}

The objective of this study is to conduct a floristic survey and a vegetation analysis of the Bighorn Canyon National Recreation Area (BCNRA) located in the northern part of the Bighorn Basin of northern Wyoming and southern Montana. The study will include the preparation of a vegetation map which, along with other ecological information, should be useful for resource management. Three phases for this work were envisioned in the original proposal:

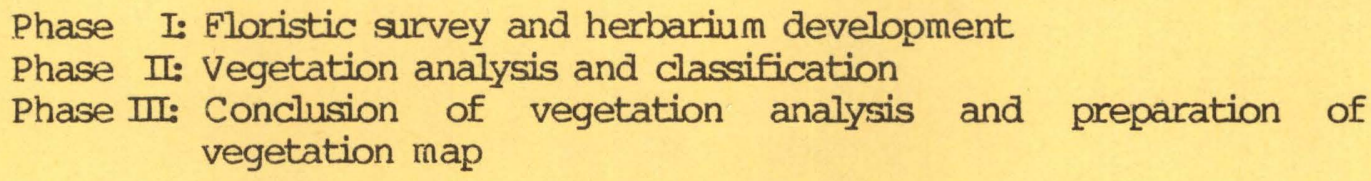

Phase I is on schedule and nearly completed, with approximately 750 species having been identified using standard references and the Rocky Mountain Herbarium of the Department of Botany, University of Wyoming. Specimens of each species are being mounted and labeled at this time. One set of the specimens and a report on the BCNRA flora will be submitted to the BCNRA Headquarters before May 1, 1984.

Plans for the initiation of Phase II are underway. 